\title{
Using a morpho-functional approach to assess phytoplankton dynamics in two adjacent high-mountain lakes: a 10-year survey
}

\author{
Renata TREVISAN, ${ }^{1}$ Marco PICARELLA,${ }^{1}$ Frank B. DAZZO,${ }^{2}$ Stefano BONA,${ }^{3}$ Giuseppe MORABITO,${ }^{4 *}$ \\ Andrea SQUARTINI ${ }^{3}$
}

\begin{abstract}
${ }^{1}$ Department of Biology, University of Padua, Viale G. Colombo 3, 35129 Padova, Italy; ${ }^{2}$ Department of Microbiology and Molecular Genetics, Michigan State University, East Lansing, MI 48824, USA; ${ }^{3}$ Department of Agronomy, Food, Natural Resources, Animals and Environment, DAFNAE, University of Padua, Viale dell'Università 16, 35020 Legnaro, PD, Italy; ${ }^{4} \mathrm{CNR}$ Institute of Ecosystem Study (ISE), Largo Tonolli 50 Verbania Pallanza, Italy

*Corresponding author: g.morabito@ise.cnr.it
\end{abstract}

\begin{abstract}
Colbricon Superiore and Inferiore are two small adjacent high-mountain lakes located in the Paneveggio Natural Park (Italy). The lakes differ by size and depth while sharing the same bedrock setting and catchment basin. Changes in the phytoplankton communities were studied over a 10-years period to individuate which environmental variables would determine the main differences in biotic assemblages across time and between the two lakes. The study was conducted with fortnightly samplings, assessing the density and biomass of algal taxa. Relationships of each of the biological variables with water temperature, $p H$, conductivity, transparency, water level, previous week rainfall, and relative water column stability were analyzed by correlation and regression analyses, cluster analysis, and by canonical correspondence analysis. The most significant variables resulted air temperature, hydrologic water level and pH. The smaller Colbricon Inferiore had about double the amount of phytoplankton density and biomass than did the larger Colbricon Superiore. The same lake had higher diversity and lower evenness in structure of the phytoplankton community. Notwithstanding their proximity each lake appears to follow independent species composition dynamics, however parallel patterns were interestingly revealed when data were analyzed by pooling taxa into morpho-functional groups. Morpho-functional groups (MFGs) 1b, 3a, 6b, 7a, 9b were differentially most abundant in warm periods, while $2 c, 3 b, 11 c, 5 e, 10 a$ prevailed in cold years. MFGs $1 b, 2 d, 3 a$ and $3 b$ were more characteristic of Lake Colbricon Superiore, while Colbricon Inferiore preferentially featured MFGs 5a, 5e, 9a, 9b, 10a, 11a and 8a. The role of the meteo-climatic parameters was pointed out in driving the different patterns observed in the two lakes.
\end{abstract}

Key words: High-mountain lakes, Lakes Colbricon, phytoplankton ecology, long term survey, morpho-functional groups.

Received: October 2013. Accepted: March 2014.

\section{INTRODUCTION}

The study of phytoplankton ecology encounters particularly useful settings in high mountain lakes (Lami and Boggero, 2006). In Europe a number of such occurrences is offered by the Alps, where a several small-sized natural basins (areas $<0.5 \mathrm{~km}^{2}$ ) are available. Their origin is in many cases referred to glacier-driven phenomena, which lead to sequences of the so called cirque lakes (Barbanti et al., 1993). Their formation is relatively recent and their shallow waters, whose regime is regulated by snow melting and rain, experience conspicuous fluctuations. (Mosello et al., 2000).

The harsh physical conditions, characterized by lifelimiting temperatures and cyclic lake surface freezing, are reflected by a sesonality in water chemistry composition (Nauwerck, 1994; Koinig et al., 1998) in turn affecting lake biota (Fott et al., 1999; Hinder et al., 1999). Depending on the surrounding lithological composition, and in particular under acidic bedrock situations, waters of such lakes are poorly buffered making them prone to acidification (Bog- gero et al., 1996). As these habitats are exposed to several perturbations and encompass considerable biodiversity, they qualify as sensitive and useful warning proxies of environmental changes in relation to global climate variation or other shifts (Nauwerck, 1994; Schmidt et al., 2004). Knowledge acquired from the biology of high mountain lakes becomes therefore a useful measure to model the effects of large-scale phenomena and to prompt consequent actions within conservation and prevention policies (Koinig et al., 1998; Catalan et al., 2009; Cabrera et al., 1997; Halac et al., 1997; Curtis et al., 2009). Phytoplankton occurring in these high-altitude basins is not endowed with specific taxa nor endemisms but rather undergoes a selection over the broad array of species living in larger freshwater bodies of less elevated locations (Nauwerck, 1966; Catalan et al., 2009). Traits promoting algal persistence in these stressful conditions include the capability to endure the alternance of long freezing periods and brief vegetative seasons, wide annual variation in light regime from summer to winter, low nutrient status and fast water chemistry variations 
(Salmaso and Decet, 1997). Among the strategies involved, volume reduction is reported (Tilzer, 1972) along with efficient motility for dispersion purposes (Pechlaner, 1971; Reynolds et al., 2002). The overall phytoplankton biovolumes of these lakes tend to be moderate, with increases observed in summer or fall (Nauwerck 1966, Rott 1988, Kernan et al., 2009 Catalan et al., 2009). In ecology, the comparison of environments differing in size allows to verify possible species-area relational trends. In this respect the incremental differences in expected species number in lakes have been studied for fish (Eadie et al., 1986) as well as for phytoplankton (Smith et al., 2005) and the corresponding power law relationships have been defined.

In the present study, we investigated two adjacent high-mountain lakes, Colbricon Superiore (CS) and Colbricon Inferiore (CI), which offer an interesting configuration to investigate differences in waterbodies lying within the same landscape and under equal geochemical influxes. The study presented here extends over 10 consecutive years throughout which the lakes were sampled with consistent intensity (about fortnightly in the ice-free periods), providing a large dataset if compared to most standards of phytoplankton ecological studies. Accounts of this survey, focusing on the taxonomical groups of the diatoms and dinophyceae, have been previously presented (Trevisan et al., 2010, 2012). In the present paper we have covered the whole phytoplankton composition of both lakes, analyzing the species composition and the structure of functional phytoplankton groups proposed by Salmaso and Padisák (2007). The influence of the environmental variables on the phytoplankton structure was tested, with the main goal to establish whether two nearby lakes, although lying in an environmentally-isogenic setting, would develop compositionally-unrelated phytoplankton communities due to intrinsic peculiarities and, possibly, to a different response to environmental variability. Moreover, the availability of a long-term dataset allowed analyzing not only the seasonal fluctuations, but also the response over longer time scales, taking into account the role played by the meteo-climatic parameters. The study is focused on morpho-functional phytoplankton groups, because they provide a clearer picture of the phytoplankton structure and functions, making easier the comparison of the assemblages in the two lakes and the identification of differences or similarities under the variability of the habitat conditions.

\section{METHODS}

\section{The site}

Details on Colbricon Superiore (1922 m asl, $\left.46^{\circ} 16^{\prime} 53.41^{\prime \prime} \mathrm{N} ; 1^{\circ} 45^{\prime} 55.27^{\prime \prime} \mathrm{E}\right)$ and Colbricon Inferiore (1910 m asl, 46 $\left.{ }^{\circ} 17^{\prime} 00.80^{\prime \prime} \mathrm{N} ; 1^{\circ} 45^{\prime} 56.18^{\prime \prime} \mathrm{E}\right)$ have been previously reported, with respect to geology, zooplankton and macroinvertebrates (Trevisan and Rosso, 1999), surrounding vegetation (Festi and Prosser, 2000), temperature and water chemistry fluctuations (Trevisan et al., 2010). The area and volume of Lake CS $\left(0.024 \mathrm{~km}^{2}\right.$ and $\left.0.13 \mathrm{~km}^{3}\right)$ are respectively nearly double and triple than those of Lake CI $\left(0.013 \mathrm{~km}^{2}\right.$ and $\left.0.05 \mathrm{~km}^{3}\right)$. Their respective maximum depths are 12 and $8 \mathrm{~m}$, and their respective mean depths 5.4 and $3.8 \mathrm{~m}$. The distance separating the two lakes, which share the same catchment basin, is less than $50 \mathrm{~m}$. An outflow from Lake CS directly conveys its water into Lake CI which lies $12 \mathrm{~m}$ below. The lakes are dimictic, undergoing complete mixing in spring and autumn.

\section{Field methods and laboratory analyses}

Both lakes were monitored and sampled over a decade. As these lakes generally freeze from November to May, the sampling scheme represented the ten ice-free periods between years 1998 and 2007, corresponding to a sampling interval of every two to three weeks. Integrated samples from the whole water column for analysis of phytoplankton density and biomass were sampled by a plastic flexible hosepipe siphon tube. The schedule involved on average 7 sampling dates each year, yielding a total of 69 samplings per lake. Hydrometric level, air and water temperature, transparency, surface water $\mathrm{pH}$ and conductivity were measured in situ.

Trophic classification of the lakes was defined using indices based on Secchi disk transparency and total phosphorus concentration, according to Hakanson (1980) and to the OECD model (1982). Water samples for taxonomic analyses were collected with a $25 \mu \mathrm{m}$ plankton net. Samples were fixed with Lugol's solution and were examined by brightfield light microscopy using an inverted microscope at 400x magnification, in accordance with the Ütermohl technique (Ütermohl, 1958), and by SEM for some specific identifications. Population volume was estimated by multiplying known reference biovolumes for the abundance of the different taxa identified. Reference data and taxonomical keys were based upon Popowsky and Pfister (1990), and Hansen and Flaim (2007). Relative Thermal Resistance to Mixing (RTRM) was calculated as described by Wetzel (2001). Cluster analyses were performed using the Past software package (Hammer et al., 2001). In order to examine correlations between variations in algal fluctuations and environmental parameters, Pearson Product moment correlation and regression analyses, were performed by CoStat software using as outcome variables the density and biomass of either taxonomical ranks or morpho-functional groups, in each of the two lakes. Ecological indices of community structure and pairwise similarity and dissimilarity coefficients (\% Proportional Similarity and Bray-Curtis distances) were computed using an in-house Center for Microbial Ecology Image Analysis System (CMEIAS ${ }^{\odot}$ ) Data Analysis Tool- 
pack addin (Dazzo et al., 2011) operating within Excel ${ }^{\circledR}$.

The relationships among morpho-functional groups and environmental variables were explored by means of Canonical Correspondence Analysis (CCA; CANOCO 4.5), following the prescriptions reported in terBraak and Smilauer (2002). The following environmental variables were included in the analysis: $\mathrm{pH}$, conductivity (COND), Secchi depth, hydrologic water level (LEVEL), amount of rainfall (RAIN) in the prior eight days, air temperature (AIR_T), surface water temperature (SWAT_T), relative water column stability (RTRM, according to Wetzel, 2011). Before the computation, the biovolumes of the single morpho-functional groups (MFG), as well as the value of the environmental variables, were transformed in percentage values, after calculating their double square root. Such transformation was adopted to obtain a comparable range of values in the environmental data and to reduce the weight of the most abundant groups (Field et al., 1982). Transformed variables were tested for normality (Shapiro-Wilk, W): some of the variables did not follow a normal distribution after the transformation. However, for a sufficiently large sample size, results from a CCA are quite robust to violation of the normality assumption (Shore, 2005). The significance of the axes obtained by the CCA analysis was tested by means of Monte Carlo test with 499 permutations (terBraak and Smilauer, 2002).

\section{RESULTS}

\section{Water chemical and physical analyses}

Detailed data on the fluctuation of the temperature and on their chemistry during the decade under study have been previously reported (Trevisan et al., 2010, 2012). The mean water temperatures for the whole icefree period were $11.17^{\circ} \mathrm{C}$ for $\mathrm{CS}$ and $11.35^{\circ} \mathrm{C}$ for $\mathrm{CI}$. The RTRM values showed, over the ten years period, an average value of 50.34 for CS and 36.55 for CI. In both lakes the average $\mathrm{pH}$ values were close to neutrality and the mean conductivity was low, consistent with a limited salinity condition. During the period examined, both lakes were mesotrophic, with mean transparency values of 5 and $4.15 \mathrm{~m}$ for $\mathrm{CS}$ and $\mathrm{CI}$, respectively.

\section{Phytoplankton composition}

The microscopical examinations of the 138 integrated samples collected in both Colbricon Lakes during the decade of study revealed a morphological richness of 128 different phytoplankton taxa. One hundred and eleven taxa were found in Lake CS and 104 in Lake CI, among which 83 taxa were shared by both lakes. Consequently, 28 lake-specific taxa were found in Lake CS and 21 in Lake CI. Their distribution of abundance among the main algal taxonomical classes are shown in Supplementary Tab. 1, along with their affiliation to the MFG defined by Salmaso and Padisák (2007). The proportion of each phytoplankton class and the differences between lakes throughout the 10 years are visible in Figs. 1 and 2. In terms of mean biomass for the whole algal load, the smaller Lake CI supported a mean total biovolume of phytoplankton that was nearly double that of the deeper upper lake $\left(639.0 \mathrm{~mm}^{3} \mathrm{~m}^{-3}\right.$ in CS vs $1166.7 \mathrm{~mm}^{3} \mathrm{~m}^{-3}$ in $\left.\mathrm{CI}\right)$. Such remarkably higher values displayed by the smaller lake are synoptically appreciable by comparing the histograms in Figs. 1 and 2. In terms of presences and community richness, the mean number of taxa identified per single sampling date was 23.8 in Lake CS and 27.0 in Lake CI. The minimum richness observed on a single occasion was 9 in Lake CS and 13 in Lake CI. The maxima were 41 and 39 , respectively.

In order to evaluate the difference in distribution of abundance, data were analyzed to compute indices of community structure (richness, dominance, diversity and evenness in distribution of abundance). These are shown in Tab. 1 and concur to indicate that Lake CI has trends of higher phytoplankton richness and diversity, accompanied by lower dominance and evenness in its phytoplankton communities. Different indices are reported to cover possible alternative abundance models. The degree of variation of the communities was assessed by performing individual community comparisons between the different

Tab. 1. Values (means of the 69 samplings) of a series of 6 ecological indices of community structure. Each single-date community was subjected to the analysis of the multiple set of indicators.

\begin{tabular}{lccc}
\hline Diversity index & Means CS* & Means CI* & Difference \\
\hline Chao 1 richness $\left(\mathrm{S}_{\text {Chao-1 }}\right)$ & 25.091 & 29.135 & 4.044 \\
Berger-Parker's dominance (d) & 0.416 & 0.415 & -0.001 \\
Shannon-Wiener's diversity (H', log(E)) & 1.881 & 1.934 & 0.052 \\
Brillouin's diversity (HB) & 1.839 & 1.888 & 0.048 \\
Simpson's evenness (E $\left.\mathrm{E}_{1 / \mathrm{D}}\right)$ & 0.221 & 0.196 & -0.026 \\
Brillouin's evenness (E) & 0.608 & 0.598 & -0.009
\end{tabular}

CS, Colbricon Superiore; CI, Colbricon Inferiore. *Means of the whole 10-years period were obtained and compared to evaluate the difference (CS CI values). For a compendium on the definitions of ecological indicators used, and the differences in their diagnostic values, see Magurran (2004). 
samplings. The array of species data (presence and abundance) of each taxon within each of the 138 samplings was compared for each combination for a total of 9611 individual pairwise comparisons. Similarity (\% Proportional Similarity, Sorensen and Jaccard indexes) and Distance evaluators (Bray Curtis, Horn, Chord) were calculated. Data for the former two indexes of each category (Proportional similarity and Bray-Curtis Distance) are shown in Tab. 2. Results indicate that the degree of similarity in phytoplankton community structure of the two lakes on the same sampling dates is very low $(22.04 \%)$ in comparison to the degree of similarity occurring within the same lake in subsequent samplings of the same year (45.18\% in CS and $53.06 \%$ in CI). An abrupt change in community composition is however imposed by the winter freezing representing a 5-6 months pause when the level of proportional similarity in subsequent samplings (the last community before winter $v s$ its corresponding one after winter) drops down to 27.90 for CS and 20.14 for CI.

In order to assess in which years were the assemblages less fluctuating across the ice-free period (May to November) we reported the mean of all pairwise comparisons between community samplings carried out within the same year in each of the two lakes. This analysis revealed that in 1998 and 1999, Lake CI was more stable than CS in community compositional shifts. The overall within-year means yields for C.I. $46.85 \%$ (1998) and $42.65 \%$ (1999), and for Lake CS were $23.40 \%$ and $28.18 \%$, respectively, for the same years (Tab. 2). In order to identify instead which years produced more conservative outcomes than the previous year, and in which years would the highest changes in community arrays occur, we calculated the mean of all pairwise comparisons between all community samplings recorded within a given year versus all those recorded in the following year, all within the same lake. For example, both lakes, the passage from 2002 to 2003 was the least impacted as it leaves communities that match the prior year at levels of $40.05 \%(\mathrm{CS})$ and $34.78 \%(\mathrm{CI})$. In contrast, the transition from 2003 to 2004 caused the most dramatic alterations of the whole period by reducing similarities to $8.60 \%$ and $15.23 \%$, respectively.

\section{Cluster analyses}

Clustering based on the phytoplankton assemblages of the 69 sampling dates of each of the two lakes was done by the Paired Group Method, using Bray-Curtis Distances and

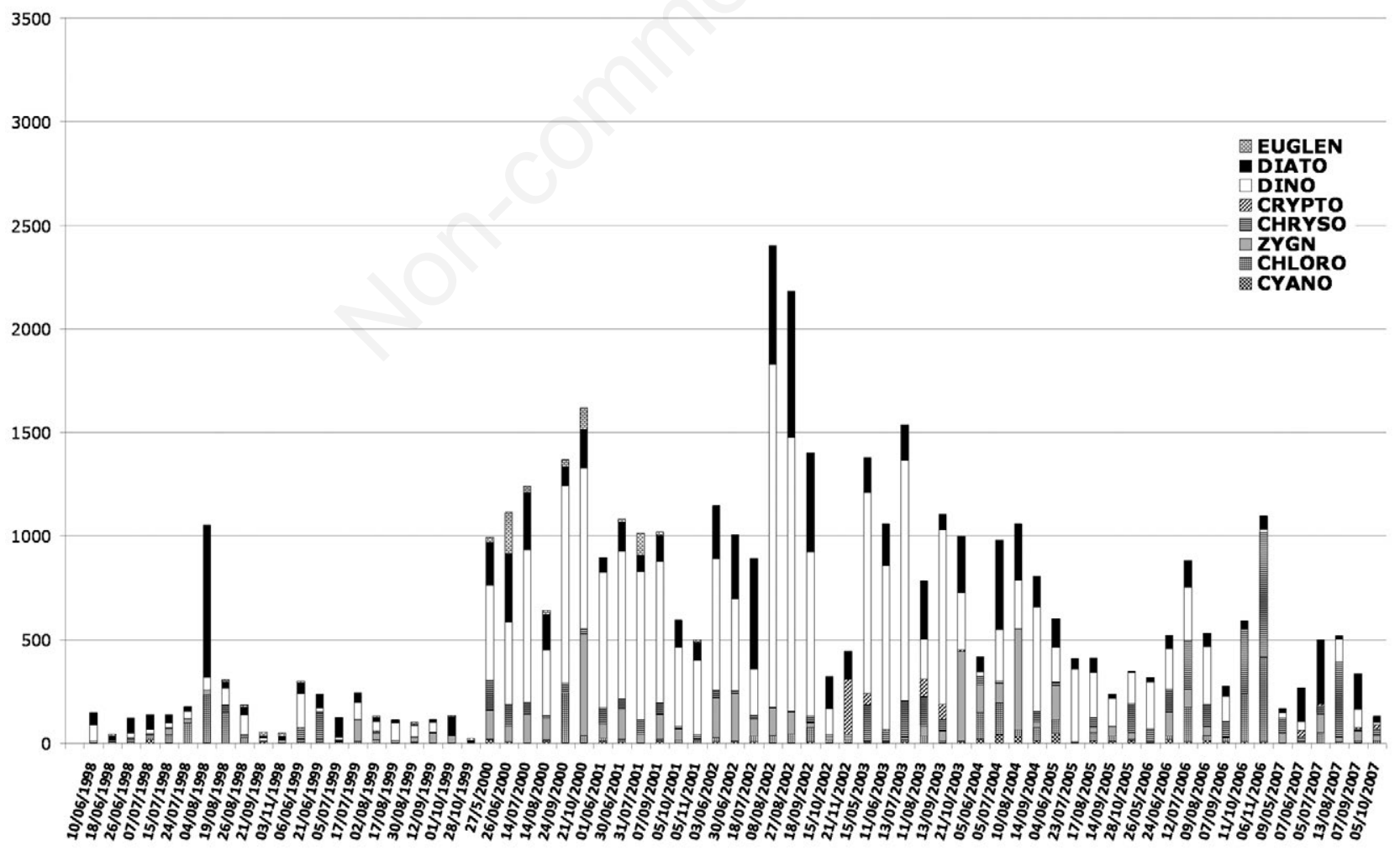

Fig. 1. Biovolumes $\left(\mathrm{mm}^{3} / \mathrm{m}^{3}\right)$ recorded at each sampling date for the different taxonomical phytoplankton groups in Lake Colbricon Superiore. 
transforming the data by the second square root of the biovolume. Data were treated either as all individual taxa or pooled into morpho-functional groups. The two approaches highlighted remarkably different outputs. The results of the Cluster Analysis based on species biovolumes (Supplementary Fig. 1) yields a smooth grouping of the sampling years, while those based on the functional groups the sampling belonging to the same year appear scattered across the different phenons while a more consistent clustering trend arises for the water temperature variable. It appears that taxonwise, the populations of the two lakes follow independent dynamics with little or no recurring species in corresponding seasons of different years, but in contrast, they exhibit a degree of seasonality when data are analyzed by the morpho-functional groups criterion.

\section{Morpho-functional group synchrony across lakes}

Under the term of MFG synchrony we define the degree of similarity in the fluctuation of a given morpho functional group in Lake CS and Lake CI. As regards general trends the most abundant MFG were $7 \mathrm{~b}(30.57 \%$ within the cumulated algal biovolume of the whole 10years period in CS and $29.81 \%$ in CI, followed by 1 b (CS
$14.25 \%$ and CI $13.65 \%$ ) and by $6 \mathrm{~b}$ (CS 9.70\%; CI $12.57 \%$ ). These three groups accounted for almost two thirds of the total production, with a fair consistency in both lakes, as in both $7 \mathrm{~b}$ was the dominant MFG with a declining kinetics in the autumn sampling. The relative proportions of $1 \mathrm{~b}$ and $6 \mathrm{~b}$ fluctuated alternatively in favor of one or the other and not in a particularly joint fashion in the two lakes. The extent of coordinated fluctuations of morpho-functional groups in the two lakes shows concerted dynamics in about half of the MFG, including some of the most abundant ones.

\section{Canonical correspondence analysis}

The canonical correspondence analysis (CCA) was performed for the two lakes independently: the ordination along CCA axis 1 and 2 explained $56 \%$ of the variance for MFG-environment relationship for Lake Colbricon Superiore and 70\% for Lake Colbricon Inferiore, respectively. The most significant variables included in the model, identified through the Monte Carlo permutation test, were air temperature (AIR_T; $\mathrm{P}=0.086$ ), hydrologic water level (LEVEL; $\mathrm{P}=0.040$ ) and conductivity (COND; $\mathrm{P}=0.032$ ) in Lake Colbricon Inferiore. None of the environmental

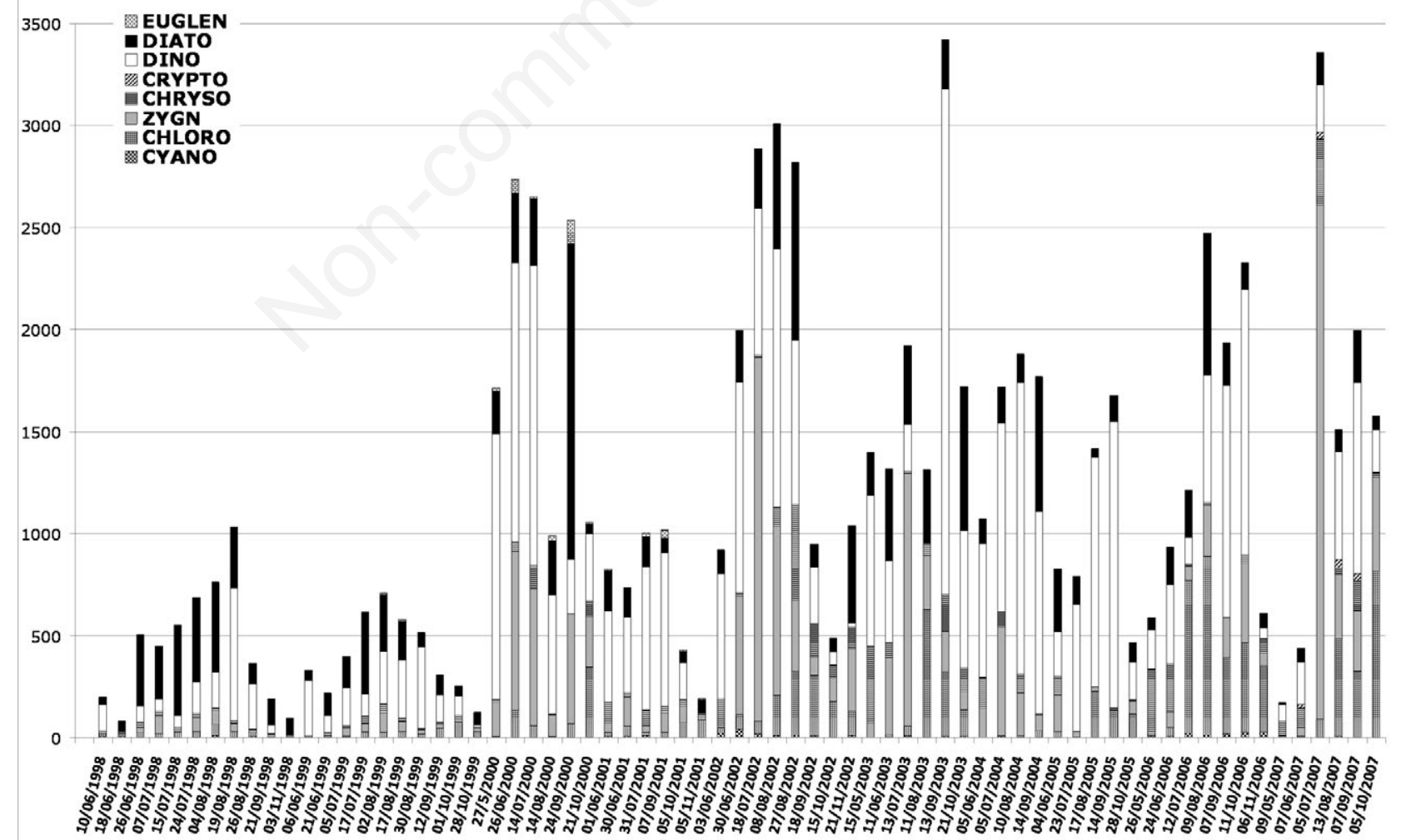

Fig. 2. Biovolumes $\left(\mathrm{mm}^{3} / \mathrm{m}^{3}\right)$ recorded at each sampling date for the different taxonomical phytoplankton groups in Lake Colbricon Inferiore. 
variables was pointed out as the most significant in Colbricon Superiore. The ordination biplots (Fig. 3) show that, in Lake CS, the $\mathrm{x}$-axis is related to conductivity and $\mathrm{pH}$ on the negative side, whereas there is not a clear relationship of a single variable with the positive side. The yaxis is related, on the positive side, to water level and rainfall amount and to temperature on the negative one. In Lake $\mathrm{CI}$, the driving variables are, on $\mathrm{x}$-axis, $\mathrm{pH}$ (negative side) and water level (positive side), whereas temperature is the driving variable for the y-axis. Physical parameters seem to play a key role in both lakes, although in Lake CI the distribution of MFG appears strongly driven by the water level fluctuations and by its effect on the water chemistry. In fact, in this lake, when water level is rising, $\mathrm{pH}$ drops, probably because some acidic chemical compound is flushed to the lake with the runoff. The phenomenon is consistent with the quartz nature of the rocks in the surrounding catchment basin, although this response is not evident in Lake CS, where the opposite relationship between conductivity and temperature could be related to an increased supply of solutes to the lakes just after the ice melting.

The ordination biplot of Lake CI shows that most of the MFGs stay in the upper part of the diagram, with a positive relationship with the $\mathrm{pH}$ vector. Such relationships can be explained by a seasonal pattern, although we should take into account that, over a ten years period, the climatic variability may determine yearly fluctuations of the hydrologic parameters, thus masking the seasonal changes. Yearly differences in phytoplankton structure can be investigated by plotting the position of samples together with the environmental variables. We analysed yearly plots, separating the samples from the two lakes, in order to evaluate possible differences between lakes. The environmental variables displayed quite a large yearto-year variability and the response of the two lakes was not homogeneous, in spite of their proximity and their hydraulic connectivity. In Fig. 4, we plotted the ordination of samples in the two lakes, in three years, selected as representative of different situations. Year 2000 was charac-

Tab. 2. Community similarity and community distance measurements.

\begin{tabular}{|c|c|c|c|c|}
\hline \multirow[t]{2}{*}{ Community comparisons } & \multicolumn{2}{|c|}{$\begin{array}{c}\text { Proportional } \\
\text { similarity } \%\end{array}$} & \multicolumn{2}{|c|}{$\begin{array}{c}\text { Bray-Curtis } \\
\text { distance }\end{array}$} \\
\hline & $\mathrm{CS}$ & CI & $\mathrm{CS}$ & CI \\
\hline Samplings at same date in different lakes $(\mathrm{CS} v s \mathrm{CI})^{*}$ & 22.04 & 0.809 & & \\
\hline Consecutive samplings in same lake ${ }^{\circ}$ & 45.18 & 53.06 & 0.611 & 0.548 \\
\hline Consecutive samplings in same lake across winter ${ }^{\#}$ & 27.90 & 20.14 & 0.796 & 0.809 \\
\hline $\begin{array}{l}\text { Samplings within same lake and same year } \\
1998 \\
1999 \\
2000 \\
2001 \\
2002 \\
2003 \\
2004 \\
2005 \\
2006 \\
2007\end{array}$ & $\begin{array}{l}23.40 \\
28.18 \\
42.89 \\
37.62 \\
50.80 \\
40.36 \\
53.26 \\
30.02 \\
59.87 \\
20.33\end{array}$ & $\begin{array}{l}46.85 \\
42.65 \\
34.82 \\
35.66 \\
42.01 \\
30.74 \\
41.46 \\
21.30 \\
30.14 \\
46.88\end{array}$ & $\begin{array}{l}0.620 \\
0.635 \\
0.526 \\
0.504 \\
0.436 \\
0.508 \\
0.491 \\
0.825 \\
0.498 \\
0.838\end{array}$ & $\begin{array}{l}0.442 \\
0.457 \\
0.552 \\
0.556 \\
0.501 \\
0.559 \\
0.530 \\
0.688 \\
0.486 \\
0.469\end{array}$ \\
\hline $\begin{array}{l}\text { Samplings within same lake across consecutive years } \\
1998 \text { vs } 1999 \\
1999 \text { vs } 2000 \\
2000 \text { vs } 2001 \\
2001 \text { vs } 2002 \\
2002 \text { vs } 2003 \\
2003 \text { vs } 2004 \\
2004 \text { vs } 2005 \\
2005 \text { vs } 2006 \\
2006 \text { vs } 2007\end{array}$ & $\begin{array}{c}16.81 \\
12.51 \\
20.29 \\
13.65 \\
40.05 \\
8.60 \\
34.95 \\
24.15 \\
29.04\end{array}$ & $\begin{array}{l}36.16 \\
12.24 \\
17.36 \\
15.43 \\
34.78 \\
15.23 \\
16.44 \\
15.41 \\
38.22\end{array}$ & $\begin{array}{l}0.852 \\
0.942 \\
0.841 \\
0.866 \\
0.624 \\
0.922 \\
0.705 \\
0.880 \\
0.764\end{array}$ & $\begin{array}{l}0.682 \\
0.902 \\
0.848 \\
0.897 \\
0.689 \\
0.876 \\
0.837 \\
0.907 \\
0.702\end{array}$ \\
\hline
\end{tabular}

CS, Colbricon Superiore; CI, Colbricon Inferiore. "Mean of each of the 69 pairwise comparisons between the communities occurring in Lake CS versus those recorded in Lake CI at the same sampling date. ${ }^{\circ}$ Mean of all pairwise comparisons between a community sampling and that of its nearest subsequent sampled date in the same lake, with the exception of the last sampling of each year against the first sampling of the following year. ${ }^{\#}$ Mean of all pairwise comparisons between each last sampling of each year (before winter) and its corresponding first sampling of the following year (after winter). $\$$ Mean of all pairwise comparisons between community samplings occurred within the same year in each of the two lakes. Mean of all pairwise comparisons between all community samplings recorded within a given versus all those recorded in the following year, within the same lake. 
terised by high water level, as a consequence of the heavy rainfall occurred in autumn 1999; $\mathrm{pH}$ values were low in both lakes and hydrological variable played a major role in this year. The phytoplankton assemblages were controlled by the same drivers in all the season and in both lakes, as shown by the ordination of samples. Year 2002, was, on the opposite, a warm year, with low rain. The position of samples in Lake CS shows a clear seasonal pattern, with summer samples related to the increasing water column stability, whereas the assemblage structure in spring and autumn samples was driven by water level, $\mathrm{pH}$ and conductivity. The response was different in Lake CI, where the increasing $\mathrm{pH}$ was the environmental variable mostly controlling the phytoplankton development. Year 2007 could represent an intermediate situation: high rain during summer did not allow for the development of a clear seasonal succession in Lake CS, whereas in Lake CI the samples are distributed along the gradient $\mathrm{pH}$-water level, according to the seasonal changes of the two parameters.

The differences in the physical and chemical environment can be responsible for some changes in the structure of the phytoplankton assemblage. In Fig. 5 we report the percentage composition of the MFG in the two lakes, in some selected cold $(2000,2006,2007)$ and warm (2001, $2002,2003)$ years. The strongest differences are in the development of MFGs 1b, 3a, 6b, 7a, 9b, showing their major peaks during the warm period and a decrease during the cold years, as well as, on the other side, other groups (2c, 3b, 11c, 5e, 10a) which increased their relative importance during the cold years, explaining the position of the 2000, 2006 and 2007 samples. Moreover, looking at Fig. 5, another interesting pattern can be pointed out: the MFGs 1b, 2d, 3a and 3b mainly characterise Lake Colbricon Superiore, whereas MFGs 5a, 5e, 9a, 9b, 10a, 11a and $8 \mathrm{a}$ are more important in Colbricon Inferiore.

\section{DISCUSSION}

The hydrological regime seems to have a major influence in determining the physico-chemical conditions of the water column. It is strongly controlled by the amount of rainfall, the main driver for the variability of the water level in the two lakes. The hydrologic level of the lakes has a direct impact on the relative stability of the water column, as pointed out by the CCA ordination diagram. A reasonable hypothesis is that, when the level is high, a shallower part of the water column can be reached by the light, resulting in a stronger thermal gradient. On the other side, when the water level is low, the temperature gradient is weaker, because even the deeper layers of the water column receive some light. Additionally, the homogenizer effect of the wind that would be more pronounced in low waters can be taken into consideration.
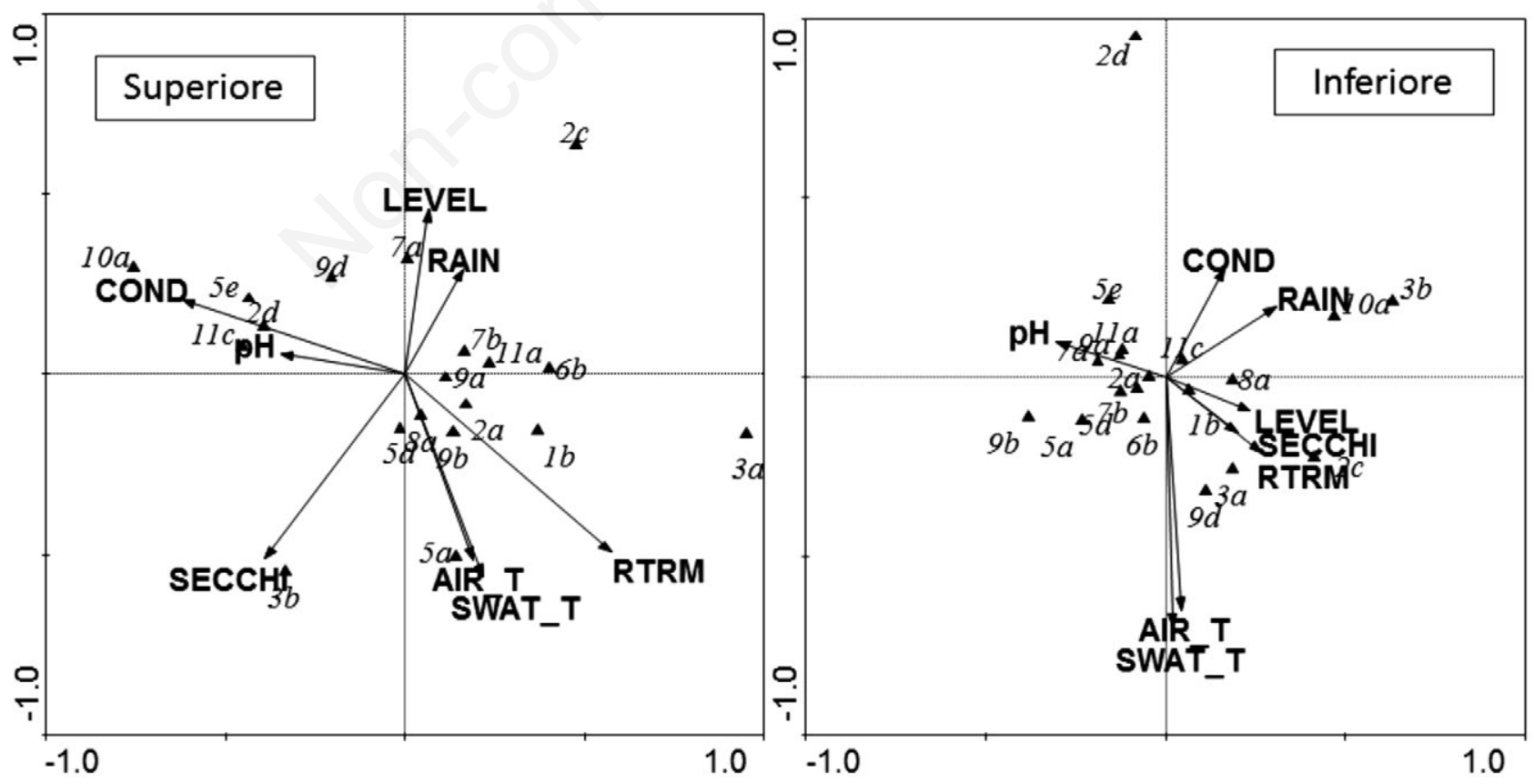

Fig. 3. Canonical Correspondence Analysis ordination biplot of environmental variables and morpho-functional groups as coded by Salmaso and Padisak (2007). Left panel, Lake Cobricon Superiore; right panel, Lake Colbricon Inferiore. See text for variable and functional groups coding. 
Therefore, we could hypothesize a relatively higher turbulence of the water column during warm years, characterized by a greater development of MFG $6 \mathrm{~b}, 7 \mathrm{a}$ and $7 \mathrm{~b}$, representing diatoms. Another important MFG, $1 \mathrm{~b}$, made up by dinoflagellates, shows an increase during warm years in Colbricon Superiore; in the CCA this group showed a slight positive relationship with RTRM, which is probably related with the better development of flagellates in stratified water columns due to their migratory ability (Reynolds, 2006; Clegg et al., 2007). Other MFGs including flagellates (2d, 3a and $3 \mathrm{~d}$ ) are more important in CS than in CI, which could be associated to the higher depth of CS that favours a more stable thermal stratification. As a consequence, the segregation of nutrients in the hypolimnion is more common in CS than in CI: this would give an advantage to the flagellated morphotypes, able to migrate, searching for the most enriched water layers (Reynolds, 2006). A morpho-functional group charac- terising only the cold years is $10 \mathrm{a}$, including colonial filamentous chlorophytes: this group is present in both lakes when the temperature is low, but the thermal stability of the water column is high, as can happen during a rainy summer period or at the beginning of autumn. In both situations the available solar radiation is probably rather low: low PAR and low mixing can give an advantage to organisms with an elongated shape such as the algae belonging to group 10a. The water input from the watershed controls the phytoplankton development affecting not only the thermal structure of the water column, but also modifying the $\mathrm{pH}$, as a consequence of both snow melting and runoff due to precipitation. This pattern, very common in mountain lakes (Cammarano and Manca, 1997; Woegrath and Psenner, 1995), has a deep influence on the structure of phytoplankton assemblages in Lakes Colbricon, where many of the Morpho Functional Groups show a strong relationship with the $\mathrm{pH}$ vector in the CCA ordi-
2000
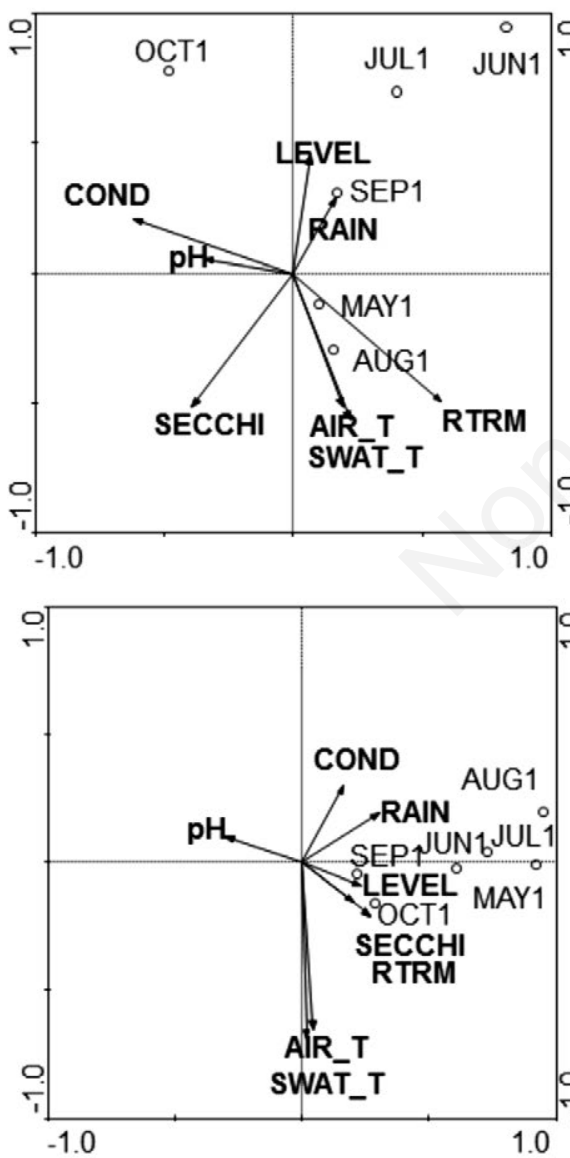

2002
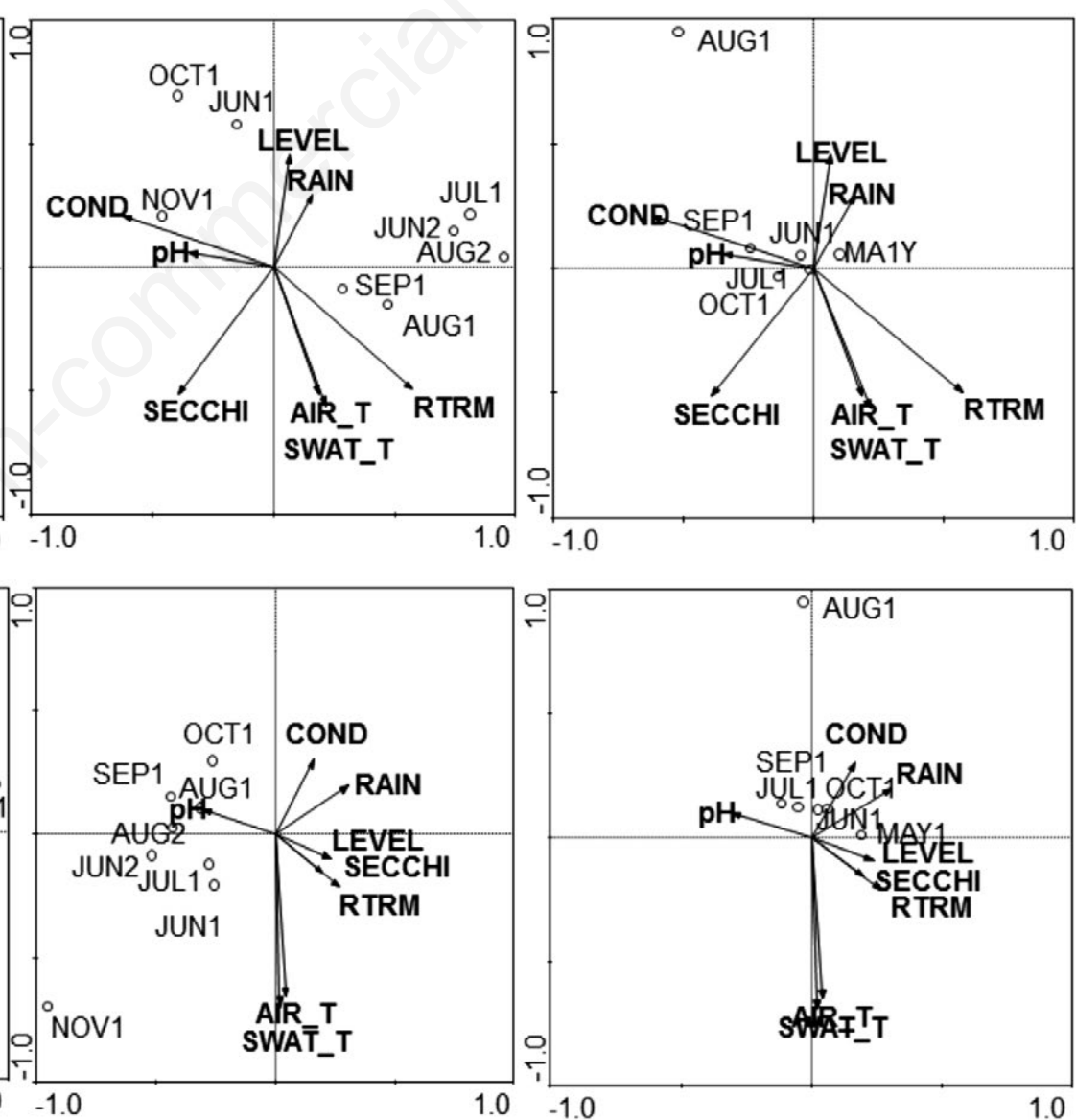

Fig. 4. Canonical Correspondence Analysis ordination biplot of samples and environmental variables in selected years: upper panels, from left to right, ordination of samples in Lake Colbricon Superiore, in the years 2000, 2002 and 2007. Lower panels, from left to right, ordination of samples in Lake Colbricon Inferiore, in the same years. See text for variable and functional groups coding. 
nation. As previously explained, the interaction $\mathrm{pH} / \mathrm{level}$ seems to affect Lake Colbricon Inferiore in particular: in this lake, the decrease of $\mathrm{pH}$, linked to certain climatic conditions, could give an advantage to the chlorophytes belonging to MFGs $8 \mathrm{a}$ and $10 \mathrm{a}$, as demonstrated by Lanfrancois et al. (2003), who carried out some enclosure experiments on the effect of acidification and nutrient addition on mountain lakes plankton. Moreover, our analyses let us hypothesise a inhomogeneous response pattern to the year-to-year fluctuations of hydrological conditions, mediated by climate. Rainfall amount, fluctuations of water level and the related effects on water chemistry are the main drivers in controlling the phytoplankton dynamics in Lakes Colbricon: situation of heavy rain and strong increase of the water level determine a similar response in the two lakes, but, on the other side, under less extreme condition, other factors, such as $\mathrm{pH}$ in Lake Colbricon Inferiore and water column stability in
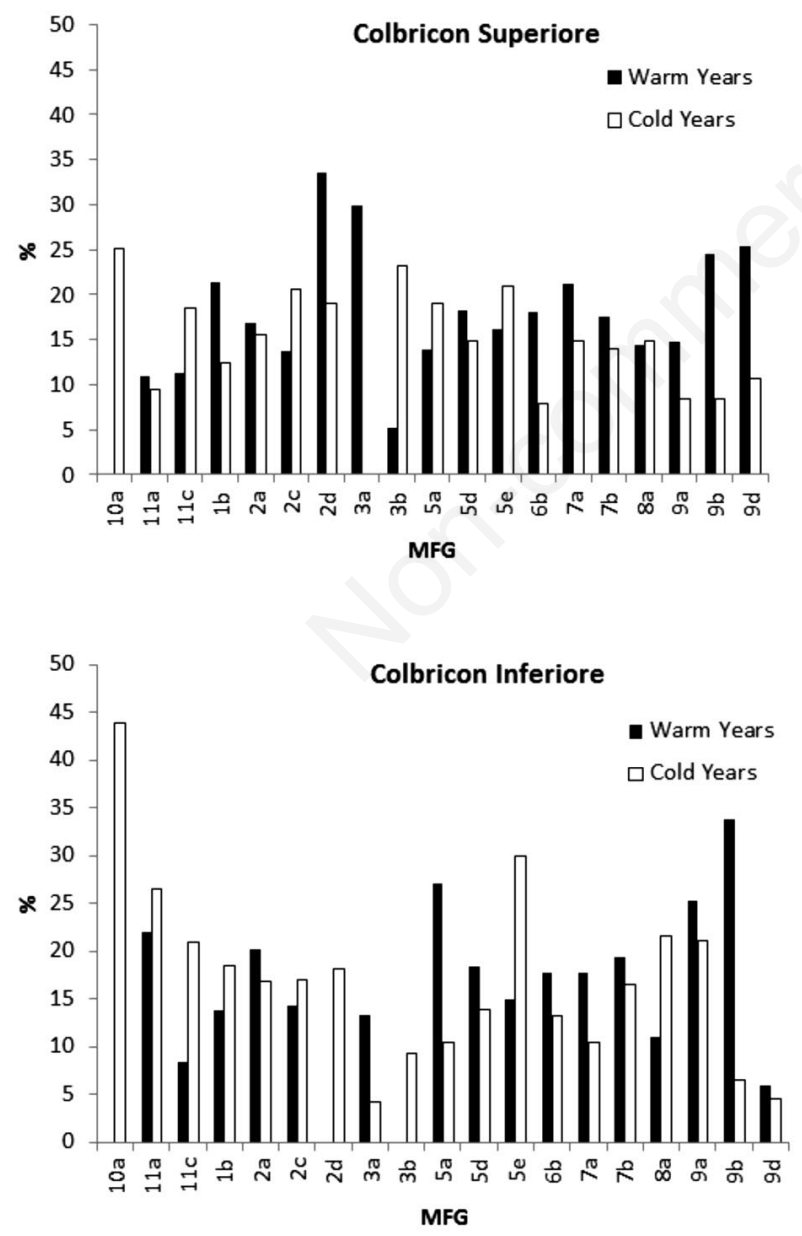

Fig. 5. Relative contribution of each MFG to the total biovolumes recorded in selected warm $(2001,2002,2003)$ and cold $(2000,2006,2007)$ years.
Lake Colbricon Superiore, can play an important role, driving the phytoplankton dynamics to different outputs in the two lakes.

In terms of production it appears that the smaller and shallower Lake CI, while sharing the same catchment basin and overall inputs of the larger lake, features a biomass almost twice as high. A possible explanation could be linked to their different depths. However, because both lakes are rather shallow, their euphotic zone in both cases extended to their entire depth. Therefore, the hypothesis that a deeper aphotic zone would dilute out the phytoplankton yield leading to lower values in Lake CS, does not explain the observed phenomenon. Alternatively, since CS has an outflow that directly conveys its water into Lake CI located at an altitude of 12 meters below, there could be a direct and continuous input of biomass enriching Lake CI However, if that were the case, one would expect that the species composition of the lower lake should broadly encompass all that occurs in the upper one plus some extra species unique to Lake CI. On the contrary, the upper Lake CS has 28 specific taxa which are not found in the lower lake, and the specific contingent of the latter is even smaller than that of CS (21) taxa. Nevertheless, since Lake CS is potentially a source of phytoplankton reintroduction into $\mathrm{CI}$, the environmental features of the latter could entail factors that negatively affect the presence of the missing taxa. Among these, consumption by zooplankton is a possible cause. Lake CI is known to host a larger variety of rotifers and higher abundance of copepods in comparison to CS, while cladocerans are present in both lakes at low density (Trevisan and Rosso, 1999). The different impact of predation, usually higher on flagellates of groups $2 \mathrm{~d}$ and $3 \mathrm{a}$, can be a further reason for the selection of large and colonial chlorophytes of MFGs 10a, 11a and 8a in Lake CI. The fact that the Colbricon Superiore effluent is the Colbricon Inferiore tributary, is anyhow to be regarded as an important link between the two lakes. Colbricon Superiore could thus influence CI in physical, chemical and biological ways. In principle, CI could be continuously seeded by CS phytoplankton. However, it is not possible to quantify the proportion of water provided by CS in time over the total volume of CI, since the outflow is partly conveyed to the lower lake upon water infiltration in soil making it difficult to measure the actual discharge load, and possible filtering effects of underground layers. Another interpretation for the higher biomass production of CI could be traced to the fact that the two basins could behave like two tanks of uneven size receiving the same load of nutrients from the surrounding catchment basin. The smaller tank would therefore end up with more concentrated supplies due to their dilution in a smaller volume of water. Chemical analyses (Trevisan et al., 2010) do not display par- 
ticular differences in this sense but it must be kept in mind that the concentration of nutrients present in the water at a given moment is a function of their dynamic consumption and incorporation into living biomass. Therefore the higher standing crop of phytoplankton biomass itself could reflect the concentration of the leftover nutrients and keep their values rather even in the two lakes. In this respect, the relatively high importance of chlorophytes and conjugatophytes in $\mathrm{CI}$ is in agreement with the results of a large scale survey of phytoplankton composition in high altitude and latitude across Europe (Tolotti et al., 2009), showing that an higher abundance of green algae was related to higher nutrient availability. To generalize the concept of these differences, a larger or deeper lake would tend to be more homogeneous timewise (hydrochemical constancy) but more heterogeneous spacewise (stratification), while a smaller or shallower lake would be more spacewise homogeneous (forced to mixing) and timewise heterogeneous (displaying frequent changes in short time frames). For example, shallow lakes have been reported to easily undergo abrupt shifts between clear and turbid states (Scheffer and Van Nes, 2007). Within such scenarios it appears that the phytoplankton assemblages undergo far more extended variations when they reside in lakes that exhibit the small/shallow situation. When analyzed individually, the single taxonomical divisions indicate that large groups of Dinophyceae and diatoms display very similar variations in both lakes, while the differences are accounted for mostly by Cyanobacteria, Chlorophyceae and Chrysophyceae, which fluctuate far more extensively in CI The lower stability of Lake CI and higher fluctuations of the environmental parameters, could provide an explanation for the higher biodiversity observed in this lake, taking into account the relationship between disturbance and diversity, according to the Intermediate Disturbance Hypothesis (Connell, 1978).

All considered, the two nearby lakes, although sitting in close proximity, sharing geology, catchment basin and climatic events, appear to evolve independent phytoplankton assemblages. In order to extrapolate, beyond the local context, a global validity of this pattern, we sought literature happenstances of equivalent setting in which adjacent basins had been compared. In fact, other lakes sharing origin, age, substrate and district, even when located very close to each other, are reported to differ in physical, chemical, and limnological features. Such occurrence is exemplified by the two lakes of El Sol and La Luna (Alcocer et al., 2004) located in central Mexico, which are located next to each other but show unrelated phytoplankton assemblages. An equally divergent case for zooplankton is reported in Japan for the two adjacent basins of Honjo and Nakaumi (Uye et al., 2004). Likewise, the two pristine forest lakes of Iso Hietajärvi and
Pieni Hietajärvi in Finland display differences in the vertical distribution of phytoplankton biomass and species composition (Holopainen et al., 2003).

\section{CONCLUSIONS}

In conclusion, the main findings arising from this analysis can be summarized as follows:

i) The smaller and shallower Lake CI, while sharing the same catchment basin and overall inputs of the larger lake, features a phytoplankton productivity almost twice as high. A reasonable explanation for the underlying cause of this difference could be the higher concentration attained by inflowing nutrients from the common catchment basin due to the smaller water volume in which they consequently dilute. A large amount of nutrient in this lake could sustain a more complex trophic web, as testified by the larger zooplankton abundance.

ii) The relatively higher trophic status of Lake CI can explain the success of the MFGs 10a, 8a and 11a, including chlorophytes, favoured by the larger nutrient supply and by their resistance to grazing. On the other side, the lower nutrient availability in the deeper Lake $\mathrm{CS}$, as well as their segregation in the lower water layers, appears to give an advantage to flagellated forms.

iii) The hydrological regime plays a major role in shaping the communities in the two lakes; it is strongly controlled by the amount of rainfall, and affecting positively the relative stability of the water column and negatively the $\mathrm{pH}$. This pattern links the system response, in terms of phytoplankton structure, with the climatic variability. In fact, although showing similar phytoplankton assemblages as concerns the dominant MFGs, the two systems differ in their subdominant MFGs, the flagellates forms characterizing CS Lake, the large and colonial chlorophytes the CI. Our results indicate a stronger response of the subdominant MFGs in the smaller $\mathrm{CI}$ to the variability of $\mathrm{pH}$ and water level, showing that, over the decade, different morphometric features of the two lakes can mediate the setting up a different phytoplankton assemblage.

iv) The phytoplankton assemblage showed a similar response in the two lakes to situation of heavy rain and strong increase of the water level; on the other side, under less extreme condition, other factors, such as $\mathrm{pH}$ and water column stability, can drive the phytoplankton dynamics to different outputs in the two lakes.

All considered, this pair of high mountain lakes, featuring a set of size-related differences within a frame of common environmental parameters, are proposed as an ideal setting for the continuation of long-term ecological studies covering an array of different biological assemblages and their responses to both global climate change and other sources of impact. 


\section{ACKNOWLEDGMENTS}

We thank the Director and all the staff at the National Park Pale di San Martino-Paneveggio for allowing and assisting the present research with valuable financial and logistic support.

\section{REFERENCES}

Alcocer J, Oseguera LA, Escobar E, Peralta L, Lugo A, 2004. Phytoplankton biomass and water chemistry in two highmountain tropical lakes in Central Mexico. Arct. Antarct. Alp. Res. 36:342-346.

Barbanti L, De Bernardi R, Giussani G, Guilizzoni P, 1993. Laghi. In: R. Marchetti (ed), Ecologia applicata, Parte I. Città Studi Ed., Torino.

Boggero A, Marchetto A, Barbieri A, Sassi A, Conedera M, Tartari GA, Mosello R, 1996. [Idrochimica dei laghi alpini del Canton Ticino (Alpi Centrali) in relazione con la chimica delle precipitazioni].[Article in Italian]. Documenta Ist. Ital. Idrobiol. 57:1-57.

Cabrera S, Lopez M, Tartarotti B, 1997. Phytoplankton and zooplankton response to ultraviolet radiation in a high-altitude Andean lake: short- versus long term effects. J. Plankton Res. 19:1565-1582.

Cammarano P and Manca M, 1997. Studies on zooplankton in two acidified high-mountain lakes in the Alps. Hydrobiologia 356:97-109.

Catalan J, Curtis CJ, Kernan M, 2009. Remote European mountain lake ecosystems: regionalisation and ecological status. Freshwater Biol. 54:2419-2432.

Clegg MR, Maberly SC, Jones RI, 2007. Behavioural response as a predictor of seasonal depth distribution and vertical niche separation in freshwater phytoplankton flagellates. Limnol. Oceanogr. 52:441-455.

Connell J, 1978. Diversity in tropical rain forests and coral reefs. Science 199:1304-1310.

Curtis CJ, Juggins S, Clarke G, Battarbee RW, Kernan M, Catalan J, Thompson R., Posch M, 2009. Regional influence of acid deposition and climate change in European mountain lakes assessed using diatom transfer functions. Freshwater Biol. 54: 2555-2572.

Dazzo FB, Liu J, Tang G, Gross C, Reddy C, Monosmith C, Zhu G, Wang J, Li M, Philips N, Baruti A, Leader I, Zamani S, Verhelst R, Radek C, Klemmer K, Farrell K, McCully J, Krasnov B, Zhou J, Smith P, Kneeshaw S, Ganesan I, McGarrell D, Leader-Wineland M, Hollingsworth R, Smucker A, Nakano S, Squartini A, Mateos P, Gantner S, Yanni, Y, 2011. CMEIAS v3.1: Advanced computational tools of image analysis software designed to strengthen microscopybased approaches for understanding microbial ecology at multiple spatial scales. All Investigator Meeting, Long-Term Ecological Research program, April 15, 2011, Kellogg Biological Station, Hickory Corners, MI, USA. Available from: http://ter.kbs.msu.edu/abstracts/414

Eadie JM, Hurly TA, Montgomerie RD, Teather KL, 1986. Lakes and rivers as islands: species-area relationships in the fish faunas of Ontario. Environ. Biol. Fish. 15:81-89.

Festi F, Prosser F, 2000. [La flora del Parco Naturale di Paneveggio-Pale di S. Martino].[Article in Italian]. Suppl. Ann. Mus. Civ. Rovereto 13:1-438.
Field JG, Clarke KR, Warwick RM, 1982. A practical strategy for analysing multispecies distribution patterns. Mar. Ecol. Prog. Ser. 8:37-52.

Fott J, Blazo M, Stuchlik E, Strunecky O, 1999. Phytoplankton in three Tatra Mountain lakes of different acidification status. J. Limnol. 58:107-116.

Hakanson L, 1980. An ecological risk index for aquatic pollution control. A sedimentological approach. Wat. Res. 14:975-1001.

Halac S, Felipe M, Camarero L, Sommaruga-Wögrath S, Psenner R, Catalan J, Sommaruga R, 1997. An in situ enclosure experiment to test the solar UV-B impact on plankton in a high altitude lake. Lack of effect on phytoplankton composition and growth. J. Plankton Res. 19:1671-1687.

Hammer Ø, Harper DAT, Ryan PD, 2001. PAST: Paleontological Statistics Software Package for Education and Data Analysis. Palaeontologia Electronica 4:1-9.

Hansen G, Flaim G, 2007. Dinoflagellates of the Trentino Province, Italy. J. Limnol 66:107-141.

Hinder B, Gabathuler M, Steiner B, Hanselmann K, Preisig HR, 1999. Seasonal dynamics and Phytoplankton diversity in high-mountain lakes (Jöri Lakes, Swiss Alps). J. Limnol. 58:152-161.

Holopainen AL, Niinioja R, Rämö A, 2003. Seasonal succession, vertical distribution and long term variation of phytoplankton communities in two shallow forest lakes in eastern Finland. Hydrobiologia 506:237-245.

Kernan M, Ventura M, Bitusík P, Brancelj A, Clarke G, Velle G, Raddum GG, Stuchlík E, Catalan J, 2009. Regionalisation of remote European mountain lake ecosystems according to their biota: environmental versus geographical patterns. Freshwater Biol. 54:2470-2493.

Koinig KA, Schmidt R, Sommaruga-Wögrath S, Tessadri R, Psenner R, 1998. Climate change as the primary cause for $\mathrm{pH}$ shifts in a high alpine lake. Water Air Soil Poll. 104:167-180.

Lami A, Boggero A, 2006. Ecology of high altitude aquatic systems in the Alps. Hydrobiologia 562:1-246.

Lafrancois BM, Nydick KR, Johnson BM, Baron JS, 2004. Cumulative effects of nutrients and $\mathrm{pH}$ on the plankton of two mountain lakes. Can. J. Fish. Aquat. Sci. 61:1153-1165.

OECD, 1982. Eutrophication of water: monitoring, assessment and control. OECD: $150 \mathrm{pp}$.

Magurran AE, 2004. Measuring biological diversity. WileyBlackwell: 264 pp.

Mosello R, Marchetto A, Brizzio MC, Rogora M, Tartari GA, 2000. Results from the Italian participation in the International Co-operative Programme on Assessment and Monitoring of Acidification of Rives and Lakes (ICP Waters). J. Limnol. 59:47-54.

Nauwerck A, 1966. [Beobachtungen über das Phytoplankton klarer Hochgebirgsseen].[Article in German]. Schweiz. Z. Hydrol. 28:4-28.

Nauwerck A, 1994. A survey on water chemistry and plankton in high-mountain lakes in northern Swedish Lapland. Hydrobiol. 274:91-100.

Pechlaner R, 1971. Factors that control the production rate and biomass of phytoplankton in high-mountain lakes. Mitt. Int. Ver. Limnol. 19:125-145.

Popovsky J, Pfiester LA, 1990. [S̈̈ßwasserflora von Mitteleuropa, Bd. 6: Dinophyceae (Dinoflagellida)].[Book in German]. Spektrum Akademischer Verlag: 272 pp. 
Reynolds CS, 2006. Ecology of phytoplankton. Cambridge University Press: $552 \mathrm{pp}$.

Reynolds CS, Huszar VL, Kruk C, Naselli-Flores L, Melo S, 2002. Towards a functional classification of the freshwater phytoplankton. J. Plankton Res. 24:417-428.

Rott E, 1988. Some aspects of the seasonal distribution of flagellates in mountain lakes. Hydrobiologia 161:159-170.

Salmaso N, Decet F, 1997. Seasonal and interannual changes of chemical characteristics and phytoplankton in a mountain lake of the eastern Italian Alps (Lake Calaita, Trentino). Int. Rev. Ges. Hydrobiol. 82:15-31.

Salmaso N, Padisák J, 2007. Morpho-functional groups and phytoplankton development in two deep lakes (Lake Garda, Italy and Lake Stechlin, Germany). Hydrobiologia 578:97-112.

Scheffer M, van Nes EH, 2007. Shallow lakes theory revisited: various alternative regimes driven by climate, nutrients, depth and lake size. Hydrobiologia 584:455-466.

Schmidt R, Kamenik C, Lange-Bertalot H, Klee R, 2004. Fragilaria and Staurosira (Bacillariophyceae) from sediment surfaces of 40 lakes in the Austrian Alps in relation to environmental variables and their potential for paleoclimatology. J. Limnol. 63:171-189.

Shore H, 2005. Response modeling methodology: empirical modeling for engineering and science. World Scientific Publ. Co. Inc.: 435 pp.

Smith VH, Foster BL, Grover JP, Holt RD, Leibold MA, deNoyelles Jr. F, 2005. Phytoplankton species richness scales consistently from laboratory microcosms to the world's oceans. P. Natl. Acad. Sci. USA 102:4393-4396.

terBraak CJF, Smilauer P, 2002. CANOCO Reference Manual and CanoDraw for Windows User's guide: Software for Canonical Community Ordination (version 4.5). Microcomputer Power, Ithaca, NY, USA.
Tilzer MM, 1972. [Dynamik und Produktivität von Phytoplankton und Pelagischen. Bakterien in einem Hochgebirgssee].[Article in German]. Arch. Hydrobiol. 40: 210-273.

Tolotti M, Manca M, Angeli N, Morabito G, Thaler B, Rott E, Stuchlik E, 2009. Phytoplankton and zooplankton associations in a set of alpine high altitude lakes: geographic distribution and ecology. Hydrobiologia 562:99-122.

Trevisan R, Pertile R, Bronamonte V, Dazzo FB, Squartini A, 2012. Dinophyceae fluctuations in two alpine lakes of contrasting size during a 10-year fortnightly survey. J. Microbiol. Biotechnol. 22:754-762.

Trevisan R, Poggi C, Squartini A, 2010. Factors affecting diatom dynamics in the alpine lakes of Colbricon (Northern Italy): a 10-year survey. J. Limnol. 69:199-208.

Trevisan R, Rosso A, 1999. [I laghi di Colbricon (Trentino Orientale): principali caratteristiche morfometriche e limnologiche].[Article in Italian]. Studi Trent. Sci. Nat. Acta Biol. 76:87-104.

Ütermohl H, 1958. [Zur Vervolkommnung der quantitaiven Phytoplankton Methodik].[Article in German]. Verh. Internat. Verein. Limnol. 9:1-38.

Uye S-I, Nakai S, Aizaki M, 2004. Potential use of extremely high biomass and production of Copepods in an enclosed brackish water body in Lake Nakaumi, Japan, for the mass seed production of fishes. Zool. Stud. 43:165-172.

Wetzel RG, 2001. Limnology. Lake and river ecosystems. 3. Academic Press: 1006 pp.

Wögrath S, Psenner R, 1995. Seasonal, annual and long-term variability in the water chemistry of a remote high-mountain lake: Acid rain versus natural changes. Water Air Soil Poll. 85:359-364. 